\title{
Labia Majora Carcinoma
}

National Cancer Institute

\section{Source}

National Cancer Institute. Labia Majora Carcinoma. NCI Thesaurus. Code C9363.

A carcinoma that arises from the labia majora. 